\title{
The escalator effect
}

\author{
EMMA MARRIS
}

\author{
Rising temperatures are changing mountain ecosystems as the heat forces some species \\ upwards - until there is nowhere left to go. Emma Marris reports on the 'escalator effect', \\ which is threatening species worldwide.
}

F or four years, butterfly net in hand, Robert Jon Wilson tramped up and down the Sierra de Guadarrama mountains in central Spain, tracking the shift in butterfly ranges as rising temperatures steadily heated the hillsides.

At the base of the mountains, Madrillenos fleeing the summer heat of the city relax on the weekends. Above them lies deciduous oak forest where horses and cattle graze. Further up, this gives way to pine forest and then alpine grasslands. Wilson recalls his fieldwork in these pleasant surroundings as "bittersweet". Despite the seemingly untouched landscapes, he found that butterfly species' ranges have crept up the mountain by an average of 200 metres since they were mapped 35 years ago. Species already living on the mountain tops are now shifting off the peaks into thin air — that is, they are going extinct. Apollo butterflies (Parnassius apollo) in the Sierra de Guadarramas, for example, are restricted to north-facing slopes above 1,300 metres $^{1}$. That's not a lot of real estate.

\section{TOO HOT TO HANDLE}

"We were quite shocked by how dramatic these changes have been," says Wilson, who is now at the University of Exeter. "I feel very privileged to have seen those species and habitats while many of them are still here."

The biological world is changing because of global warming. Most non-specialists are familiar with poleward shifts - migration routes and species distributions that are creeping north in the Northern Hemisphere and south in the Southern Hemisphere as the equator-facing edges of these historic ranges become too hot for species to handle.

The same phenomenon is happening in three dimensions, though there is less data and less media coverage for these upward trends. As the climate warms, there is a corresponding increase in temperature at any given elevation. And any species unable to take the heat - or related changes in, for example, precipitation - will generally move up the mountain towards colder climes, until they reach the top.

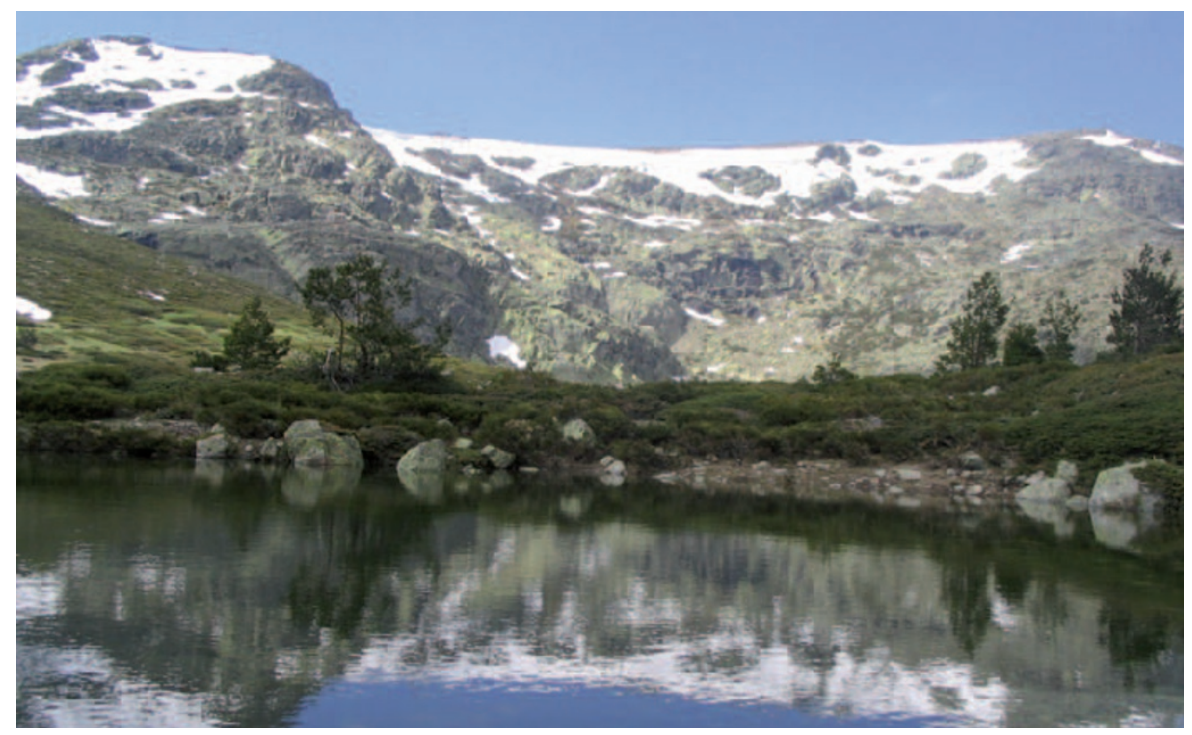

Rising temperatures are changing mountain ecosystems as the heat forces species upwards and towards extinction.

Complicating the picture is the observation that not all species adjust to temperature shifts at the same rate. Bird species may flee uncomfortably hot altitudes far before a tree-line shifts uphill. And many species may move not because they can't take the temperatures themselves, but because of the impact of climate change on other species they rely on, or because the creeping heat favours pathogens that kill them off.

"I am most concerned about species' communities being torn apart," says Stanford ecologist Terry Root. "It is all going to be quite a mishmash of things."

In the case of Wilson's butterflies, many of them have left areas that still contain the plants on which they feed in the caterpillar stage. Wilson's group probed what was pushing the butterflies uphill by bringing some eggs of the black-veined white butterfly (Aporia crataegi) from 900 metres, where the species is found now, down to 600 metres, where it used to be seen in the 1960s and 70 s. Even when the eggs were placed on shrubs like blackthorn and hawthorn, their traditional hosts, they all died. Wilson suspects that the heat killed them directly.

About fifteen years ago, according to biologist Camille Parmesan of the University of Texas, Austin, experts argued over what kinds of effects climate change would have on species. The only thing they could agree on in those early days, she says, was that "Mountain restricted species and other species that had very strict range limitations would be in trouble."

\section{AMASSING EVIDENCE}

The years since have borne out this prediction. Two kinds of evidence attest to the escalator effect, where species move steadily upward in altitude in response to a parallel shift in their climatic habitat. The first is a limited number of studies comparing species' ranges over the years and, ideally, proposing mechanisms for observed shifts. Wilson's mountain-climbing butterflies fit into this category, as do tree-lines on the move in Siberia and the Canadian Rockies. And similar trends are being observed 
across mountain woodlands in Queensland, Australia, where heat-stressed tree possums are literally falling out of the trees.

Yet another example is the American pika, a fur-ball of a rodent that lives in high mountains in the American west. The US Center for Biological Diversity is petitioning the government to list the pika as endangered as a result of climate change. They cite data showing that lower-elevation populations are disappearing. The pika is well known to be intolerant of heat; experiments in the 1970s showed that just a few hours in $27^{\circ} \mathrm{C}$ heat can strike them dead.

More complex is the case of harlequin frogs in the mountains of Costa Rica. They don't move up, but they are clearly becoming extinct in a pattern that matches changes in global climate. A current hypothesis is that they fall prey to a nasty fungus that benefits from complex changes in microclimate. The frogs stay put, but the pathogen explodes in their range, thanks to ideal growth conditions caused by climate change, including cloudiness, daytime cooling and night-time warming ${ }^{2}$.

Alan Pounds of the Golden Toad Laboratory for Conservation at the Monteverde Cloud Forest Preserve and Tropical Science Center, in Costa Rica, put the pieces together to form that hypothesis. He has worked in Central America since the 1980s, and says that changing patterns in biodiversity are evident all around him. "We can see it ourselves when we walk outside," he says. "It used to be that at a certain point you could hear one bird calling up-slope and

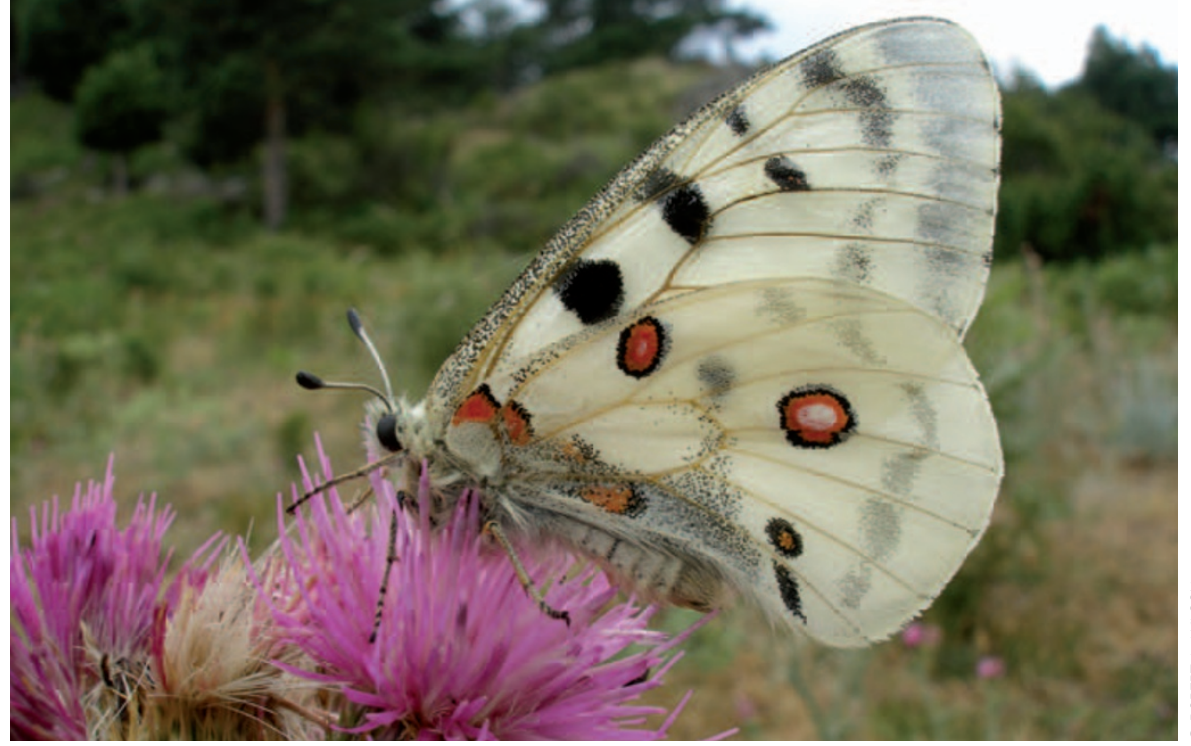

In the Sierra de Guadarrama mountains in central Spain, butterfly species' ranges have shifted upwards by an average of 200 metres since the 1970s.

another calling down-slope, and those patterns have changed."

The other kind of evidence comes from global models that estimate how many species may be in danger of extinction. Using the notion of a 'climate envelope', these models often describe the known range of a species by some more or less arbitrarily chosen climate markers, such as hottest month, coldest day of the year and seasonal rainfall.

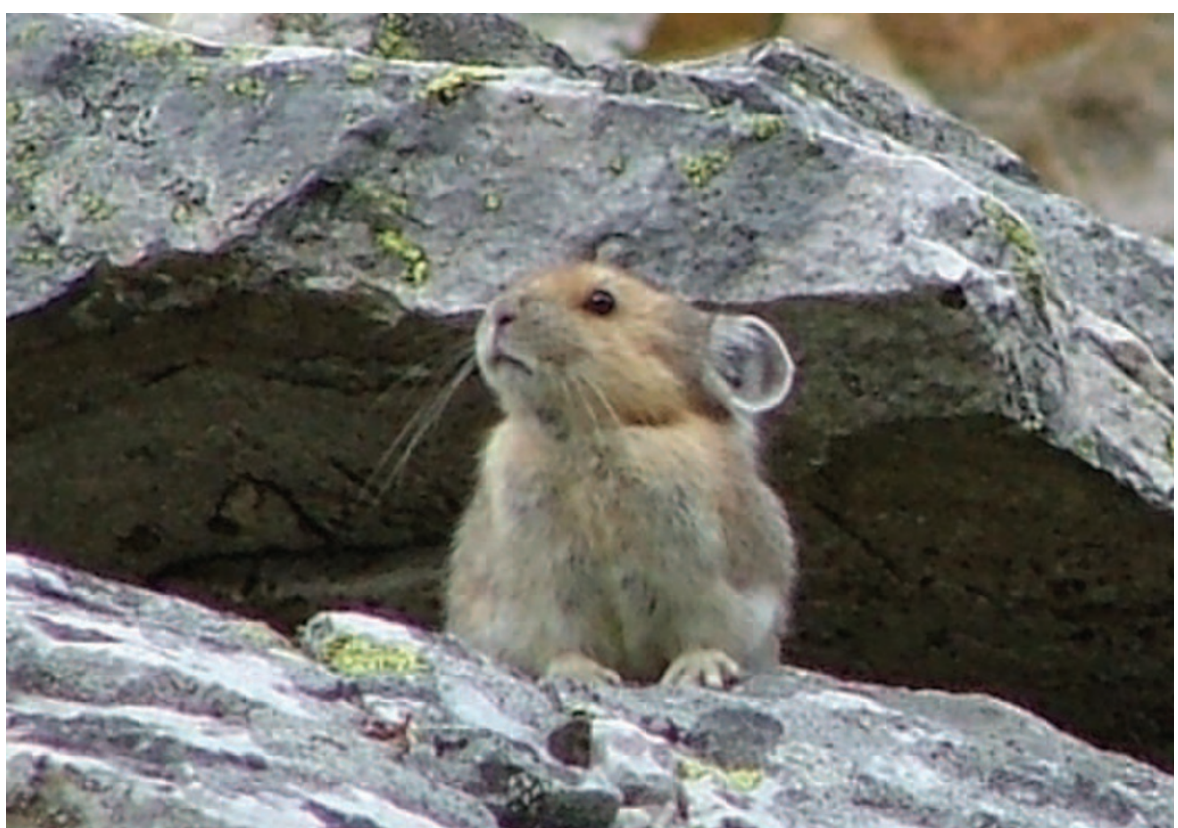

Lower-elevation populations of the American pika, a species intolerant of heat, are disappearing owing to climate change.
Models based on various warming scenarios can then be used to predict how climate patterns over land will change in the future. For some species, the climate envelope that surrounds them moves decorously poleward or upward through undeveloped land, and the species can be assumed to move with it. Often, though, the climate envelope moves into a developed area or off the top of a mountain, and the model then assumes that the species will become extinct.

\section{EXTINCTION RISK}

The most famous of these models looked at both poleward and upward movement and predicted that between $15 \%$ and $37 \%$ of species will be 'committed to extinction' by 2050. That is, some individuals may remain, but not enough for the species to recover ${ }^{3}$.

The paper was criticized by some biologists, however, for combining models that relied on different assumptions and methods. Miguel B. Araújo, a biologist at el Museo Nacional de Ciencias Naturales in Madrid, worries that the method could give an inaccurate estimate. "If you choose different statistical techniques to model the range shifts you get different results - you might get a $300 \%$ expansion or $100 \%$ contraction for the same species." He says, "They used projections in different parts of the world with different techniques and lumped them all together. They may be right, but it is just a guess."

The contentious model's first author, Chris Thomas of the University of Leeds, 
says the critics misinterpreted the paper's aims. "Most people have been totally overinterpreting it," he says. "Before we started, people talked about climate changes causing species to go extinct, and we wondered, 'what percent?' It was an order of magnitude question, and the answer was on the order of 10 , rather than $1 . "$

While Araújo argues that current methods just aren't good enough to come up with useful numbers on a global scale, Thomas believes that models such as his are good for gross analysis of trends - but that's as far as they go. "You can't trust the projection as a prognosis for an individual species," he says. And, as is often the case with complex systems, the escalator effect does not work independently. "I would personally expect climate change to have its most severe effects as a result of the interaction between habitat loss, climate change and invasive species", says Thomas.

Despite all of these caveats, many scientists feel that modelling is a compelling way of estimating the magnitude of climate effects on species. Cagan Sekercioglu, conservation biologist at Stanford University, hopes that his newly published model of bird extinctions ${ }^{4}$ will help convince the International Union for Conservation of Nature and Natural Resources (IUCN) - the body that compiles the international 'Red List' of threatened species - to put more weight on threats from climate change when evaluating the status of a species.

Prepared with three co-authors, including Stanford climatologist Stephen Schneider, the analysis found that hundreds of birds could go extinct owing to the escalator effect. "Our best guess is that climate change effects, exacerbated by habitat loss, will result in about $400-550$ land bird extinctions by 2100 , based on a $2.8^{\circ} \mathrm{C}$ warming," says Sekercioglu.

\section{Our best guess is that climate} change effects, exacerbated by habitat loss, will result in about 400-550 land bird extinctions by 2100 , based on a $2.8^{\circ} \mathrm{C}$ warming.

Cagan Sekercioglu

Just $21 \%$ of birds predicted to go extinct under the model are on the IUCN Red List.

Sekercioglu is a researcher at Stanford, but he is more likely to be found nearly anywhere else in the world where there are birds. Speaking from a field site in Ethiopia, where hyenas while away the midday watching Sekercioglu and his team band birds, he says that the extinctions he's predicting are new. "These extinctions will be in addition to the ones currently predicted," he says. "This analysis shows that quantitatively. We are hoping that elevational range will be adopted by the IUCN as another flag to predict which species may be threatened due to climate change."

Because of the global nature of climate change, there is not much that can be done about this effect at the local level. But that hasn't stopped some conservation biologists from being creative. "You can't make the mountain grow bigger, but you could think about moving species to another mountaintop that is either higher or further north," says Parmesan. "Some say, 'Well then you are introducing alien species.' The counter argument is, 'Well, should we just watch them die?"'

Emma Marris is a correspondent for Nature based in Columbia, Missouri.

Published online: 23 November 2007

doi:10.1038/climate.2007.70

References

1. Wilson, R. J. et al. Ecol. Lett. 8, 1138-1146 (2005).

2. Pounds, J. A. et al. Nature 439, 161-167 (2006).

3. Thomas, C. D. et al. Nature 427, 145-148 (2004).

4. Sekercioglu, C. et al. Conserv. Biol. (in the press).

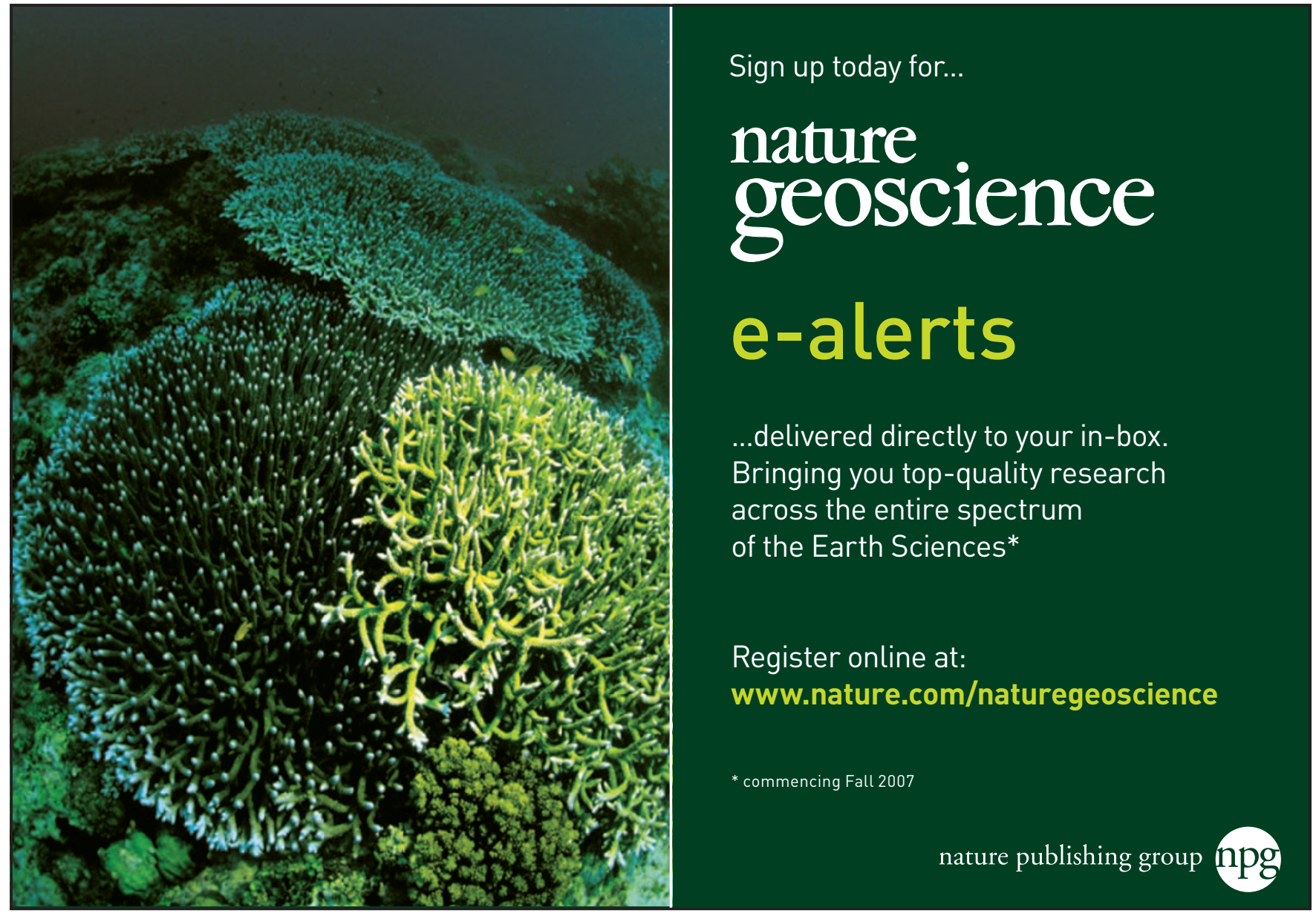




\section{The escalator effect}

EMMA MARRIS

Nature Reports Climate Change 1, 94-96 (2007)

The pika was incorrectly described as a rodent. It is one of the lagomorphs, a group closely related to rodents that also includes rabbits and hares. 